\title{
A caregiver-reported global severity assessment in pediatric atopic eczema: the Comano score
}

\author{
Mattia Giovannini', Davide Geat ${ }^{2}$, Gabriele Barlocco ${ }^{3}$, Riccardo Pertile ${ }^{4}$, Francesca Mori ${ }^{1}$, Cesare Filippeschi ${ }^{5}$, \\ Elio Novembre ${ }^{1}$, Mario Cristofolini ${ }^{3}$ and Ermanno Baldo ${ }^{3^{*}}$
}

\begin{abstract}
Atopic eczema (AE) is the most common inflammatory skin disease in infancy and its prevalence is rising worldwide. It has a wide social impact on the affected children and their families' lives. AE can have a chronic and heterogeneous course, with periods of remission and relapse of the clinical manifestations. For this reason, its severity assessment through standardized outcome measures becomes a fundamental guide for health professionals, who can manage AE following evidence-based medicine principles in their everyday clinical practice or in clinical trials.

Several scoring systems have been recognized to assess the clinical manifestations of AE, both from the physician's and the patient's point of view. Despite the scoring systems standardized for adults, there are very few published options about the expression of a patient/caregiver-centered global severity assessment specifically for pediatric AE. For this reason, the aim of our study was to evaluate a new, quick, user-friendly and feasible caregiver-reported global severity assessment for pediatric AE. Based on a 0-10 numerical rating scale in pediatric $A E$, we named this scoring system the Comano score.

We carried out a cross-sectional observational study enrolling a total of 867 patients aged from 1 to 16 years (males $49.5 \%$, mean patient's age 5.9 years, standard deviation \pm 3.6 years) with a previous doctor-confirmed diagnosis of $A E$, who underwent balneotherapy at Comano Thermal Center (Comano, Trentino, Italy). A strong correlation between Comano score and SCORing Atopic Dermatitis (SCORAD) was observed $(r=0.74, p<0.0001)$.

According to our results, the Comano score may be a promising new tool for the expression of a caregiver-reported global severity assessment in pediatric AE. However, further data are needed to confirm our preliminary findings before health professionals can use this scoring system in their everyday clinical practice to manage pediatric AE. Still, as a patient-focused measure, the Comano score may facilitate delivering person-centered care so as to define a measure for a clinical impact that can be meaningful to the subject, which is gaining importance in modern medicine.
\end{abstract}

Keywords: Scoring system, Atopic dermatitis, Comano score, Children, Person-centered care

\footnotetext{
* Correspondence: ermanno@baldo.tn.it

3"Giovan Battista Mattei" Research Institute, Stenico, Italy

Full list of author information is available at the end of the article
}

(c) The Author(s). 2020 Open Access This article is licensed under a Creative Commons Attribution 4.0 International License, which permits use, sharing, adaptation, distribution and reproduction in any medium or format, as long as you give appropriate credit to the original author(s) and the source, provide a link to the Creative Commons licence, and indicate if changes were made. The images or other third party material in this article are included in the article's Creative Commons licence, unless indicated otherwise in a credit line to the material. If material is not included in the article's Creative Commons licence and your intended use is not permitted by statutory regulation or exceeds the permitted use, you will need to obtain permission directly from the copyright holder. To view a copy of this licence, visit http://creativecommons.org/licenses/by/4.0/ The Creative Commons Public Domain Dedication waiver (http://creativecommons.org/publicdomain/zero/1.0/) applies to the data made available in this article, unless otherwise stated in a credit line to the data. 
To the Editor,

Atopic eczema (AE) is the most common inflammatory skin disease of infancy, affecting up to $20 \%$ of the pediatric population in Western countries, with its prevalence rising worldwide [1]. It has a wide social impact on the affected children and their families' lives, as it jeopardizes their daily activities, their sleep and their mental health, in addition to its direct/indirect economic costs. Moreover, the impact of $\mathrm{AE}$ is significantly increased by comorbidities, especially asthma [2].

$\mathrm{AE}$ is characterized by a chronic and heterogenous course, with periods of remission and relapse [1]. Therefore, AE severity assessment through standardized outcome measures is a fundamental guide for health professionals, who can manage AE following evidencebased medicine principles in their everyday clinical practice or in clinical trials.

According to the systematic review carried out by the international multidisciplinary initiative Harmonising Outcome Measures in Eczema (HOME), among 16 eligible tools to assess the clinical signs of AE, the Eczema Area and Severity Index (EASI) and objective SCORing Atopic Dermatitis (oSCORAD) were the ones with the highest validation. Thus, they should be the choice to evaluate outcome measures for AE signs in clinical trials [3-5].

Patient-focused measures are getting more and more important in modern medicine, characterized by a personcentered care in order to define a measure for a clinical impact that can be meaningful to the subject. On this note, a cross-sectional survey-based study analyzed different $\mathrm{AE}$ patient-reported global severity assessment measures in adults [6]. As a result, numeric rating scale (NRS) itch, PatientOriented SCORing Atopic Dermatitis (PO-SCORAD) and Patient-Oriented Eczema Measure (POEM) were proven to be reliable scoring systems to evaluate $\mathrm{AE}$ severity in clinical practice $[7,8]$. Despite the validity these tools showed, they are also quite time-consuming and not so easy for patients to understand. This can negatively impact their feasibility and use in real-life practice. However, a new, quick, easy and manageable tool called Patient-Reported Global Severity of Atopic Dermatitis has also been recently validated for clinical use in adult patients [9].

Despite the scoring systems validated for adults, there are very few published options about the expression of a patient/caregiver-centered global severity assessment specifically for $\mathrm{AE}$ in children. For this reason, the aim of our study was to evaluate a new, quick, user-friendly and feasible caregiver-reported global severity evaluation for pediatric AE. Based on a $0-10$ NRS, we named this tool the Comano score.

We carried out a cross-sectional observational study, enrolling pediatric patients aged 1 to 16 years, with a previous doctor-confirmed diagnosis of $\mathrm{AE}$, who underwent balneotherapy at Comano Thermal Center (Comano,
Trentino, Italy) from April to October 2014. All the patients with medical conditions that may contraindicate or negatively influence balneotherapy, such as cutaneous diseases (e.g. bacterial, viral or fungal infections, ulcers or skin cancer) or systemic pathologies (e.g. infectious diseases, malignancies, cardiac diseases and immunodeficiencies) were excluded from the balneotherapy, as required by the center policy and by the principles of good clinical practice in thermal medicine, and they were therefore excluded also from the study. An informed, written consent was obtained from all parents/guardians prior to including the patients in the study.

The caregivers assessed the $\mathrm{AE}$ clinical manifestations severity through a $0-10$ NRS, by answering the following physician's question: "How would you describe your AE clinical manifestations severity from 0 to 10 , where 0 (minimum score) means absence of AE signs and symptoms and 10 (maximum score) means maximum severity of AE signs and symptoms?". This score is composed of 10 units with the minimal expressible difference of 1 unit.

After that, either a dermatologist or a pediatrician evaluated the patients' clinical history and carried out the necessary dermatological examination to assess the $\mathrm{AE}$ clinical manifestations severity through SCORing Atopic Dermatitis (SCORAD) [5]. This scoring system evaluates $\mathrm{AE}$ using three different criteria: extension of the involved skin surface expressed as percentage (objective item), intensity (objective item; through the assessment of each of the following elements on a $0-3$ balance: erythema, dryness, edema/papulation, oozing/crusting, excoriation, lichenification) and subjective symptoms (pruritus during the day and sleep loss, each on a $0-10$ scale). The scores are then merged together according to the formula: "SCORAD (minimum score 0 - maximum score 103; score composed of 103 units with the minimal expressible

Table 1 SCORAD and Comano score of the study population

\begin{tabular}{ll}
\hline Patients & $\boldsymbol{n}(\%)$ \\
\hline SCORAD & $867(100 \%)$ \\
$0-15$ & $357(41.2 \%)$ \\
$15-30$ & $237(27.3 \%)$ \\
$30-40$ & $141(16.3 \%)$ \\
$40-60$ & $91(10.5 \%)$ \\
$>60$ & $41(4.7 \%)$ \\
Comano score & \\
$0-3$ & $369(42.6 \%)$ \\
$4-6$ & $300(34.6 \%)$ \\
$7-8$ & $167(19.3 \%)$ \\
$9-10$ & $31(3.6 \%)$ \\
\hline
\end{tabular}

SCORAD: SCOring Atopic Dermatitis 
difference of 1 unit $)=$ extent $(0-100) / 5+$ intensity $(0-18) x$ $3.5+$ subjective items $(0-20) "$ [5].

Data on the assessment of the AE clinical manifestations severity were collected using 4 categories $(0-$ $3,4-6,7-8,9-10)$ for the Comano score and 5 categories $(<15, \quad 15-30,31-40,41-60,>60)$ for SCORAD. The Comano score concurrent validity compared with SCORAD was assessed through simple linear regression by evaluating the Pearson's correlation coefficient between them. In the data reporting phase, descriptive statistics continue variables were presented as counts, mean and standard deviation (SD) and categorical variables as counts and percentages. The correlation was classified according to the Pearson's coefficient: $0.10-0.29$ was considered as a small correlation, $0.30-0.49$ a medium correlation and 0.50-1.0 a large correlation. Statistical data analysis was carried out using SAS software (SAS institute, Cary, North Carolina, United States of America).

A total of 867 patients were included in the study, $49.5 \%$ males and with a mean patient's age of 5.9 years ( $\mathrm{SD} \pm 3.6$ years). Comano score and SCORAD of the study population are shown in Table 1. A strong correlation between the Comano score and SCORAD was observed ( $r=0.74, p<0.0001$ ) (Fig. 1).

Despite the great epidemiological impact of $\mathrm{AE}$ in pediatric patients, there are only a few reported articles regarding patient/caregiver-centered global severity assessment in pediatric age.

A longitudinal descriptive single-center study published by Lee JY et al. [10] demonstrated Atopic Dermatitis Symptom Score (ADSS), included in a smartphone application, as a useful tool for patients or their parents to assess the severity of AE in children on a daily basis. ADSS focuses on 6 different parameters: 4 signs (dryness, erythema, oozing, oedema) and 2 symptoms (sleep disturbance and itching). They are measured on a scale from 0 ("mild") to 4 ("very severe") with a potential score ranging from 0 to 24 units with a minimal expressible difference of 1 unit. The authors pointed out how the score had strong intra-observer (test-retest) reliability [intraclass correlation coefficient $=0.82$; 95\% confidence interval $(95 \% \mathrm{CI})$ : 0.70 $0.90]$. ADSS also demonstrated a statistically significant concurrent validity $(r=0.64, p<0.0001)$ and responsiveness $(r=0.56, p<0.0001)$ compared to SCORAD.

A prospective observational multicenter experience reported by Koh MJ et al. [11] studied the correlation between Patient Eczema Severity Time (PEST), carried out daily by a caregiver, and SCORAD, in the evaluation of $\mathrm{AE}$ severity in pediatric patients from 6 months to 6 years of age. PEST is a picture-based score with 5 images associated with caregiver/patient-reported global severity assessment ranging from 1 ("not at all unhappy") to 5 ("extremely unhappy"). The authors highlighted a weakmoderate correlation between this score and SCORAD in children (ranging from $r=0.22$ at baseline to $r=0.58$ at week 12). However, they pointed out the advantages of using PEST to describe the changes in the AE severity over time, considering its higher responsiveness to modifications compared to SCORAD (PEST 33.3\%; 95\% CI: 26.0-40.5\% versus SCORAD 13.8\%; 95\% CI: 9.5-18.1\% of scale). However, it is worth noting that PEST has not been studied in children over 6 years of age.

The communication of a patient-centered global severity assessment for $\mathrm{AE}$ is challenging in pediatric patients, as parents/guardians are the ones in charge of the

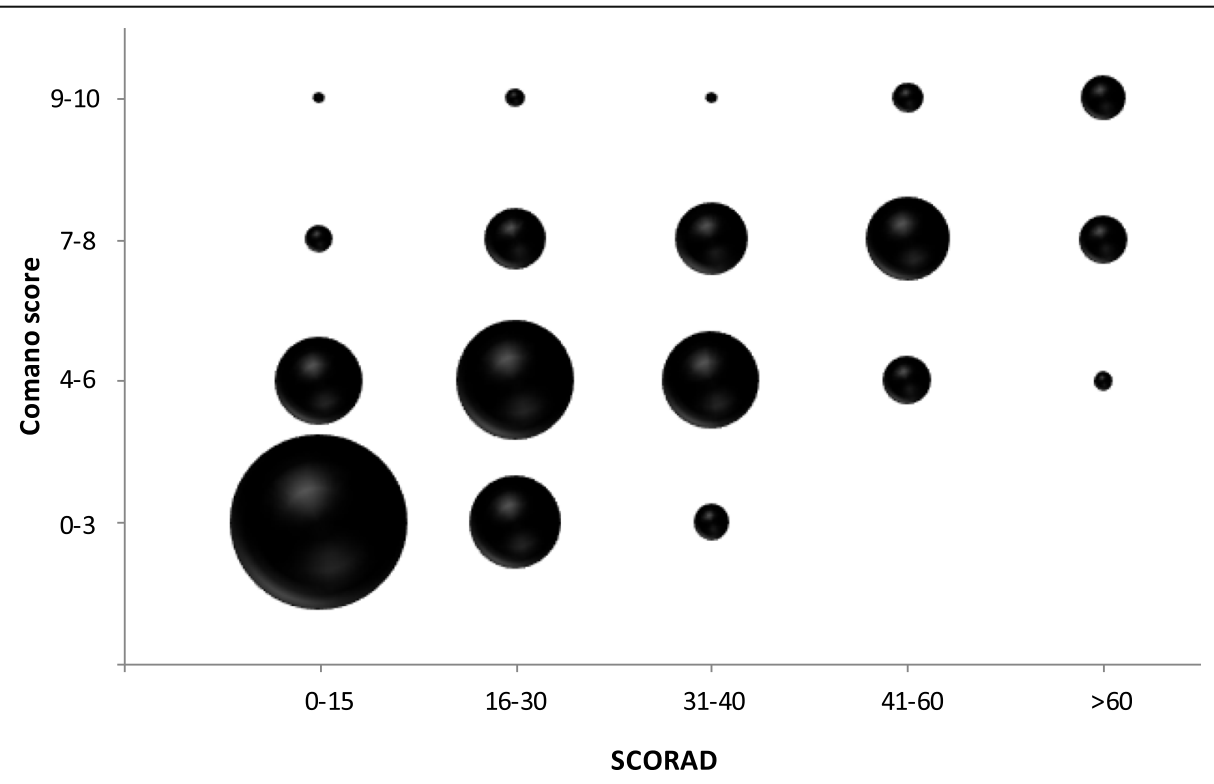

Fig. 1 Correlation between SCOring Atopic Dermatitis (SCORAD) and Comano score 
patients' care. Therefore, caregiver-centered severity evaluation seems to be the optimal alternative. From our results, the Comano score may be a promising new tool to express a caregiver-reported global severity assessment in pediatric AE. It is based on a simple $0-10 \mathrm{NRS}$, which may become a quick, easy and feasible scoring system for pediatric patient's parents/guardians.

The high number of participants is a strong point of our study, as it enabled us to demonstrate the significant concurrent validity of the Comano score compared to SCORAD in a heterogeneous study population, with patients suffering from a wide range of AE severity. However, our study inevitably has several limitations, too, mainly driven by the clinical setting in which it was implemented, i.e. admission visits for balneotherapy. For this reason, we did not have the opportunity to follow up the patients. On the contrary, it would have been helpful to study the dynamic changes of Comano score and SCORAD over time, in accordance to AE signs and symptoms modifications, and then compare the Comano score's responsiveness to SCORAD. Moreover, data about the intraobserver (test-retest) reliability would have been necessary as well to appropriately validate it. Finally, receiver-operating characteristic curve analyses should be carried out to assess the Comano score cut-off point associated with severe AE (SCORAD $\geq 40$ ).

Therefore, further data are needed to confirm our preliminary findings before health professionals can use this promising scoring system in their everyday clinical practice to manage pediatric AE. Nevertheless, as a patientfocused measure, the Comano score may facilitate delivering person-centered care so as to define a measure for a clinical impact that can be meaningful to the subject, which is gaining importance in modern medicine.

\begin{abstract}
Abbreviations
95\% Cl: 95\% Confidence Interval; ADSS: Atopic Dermatitis Symptom Score; AE: Atopic Eczema; EASI: Eczema Area and Severity Index; HOME: Harmonising Outcome Measures in Eczema; NRS: Numerical Rating Scale; OSCORAD: objective SCORing Atopic Dermatitis; PEST: Patient Eczema Severity Time; POEM: PatientOriented Eczema Measure; PO-SCORAD: Patient-Oriented SCORing Atopic Dermatitis; SCORAD: SCORing Atopic Dermatitis; SD: Standard Deviation
\end{abstract}

\section{Acknowledgements}

Not applicable.

\section{Ethics approval and consent to participate}

An informed, written consent was obtained from all parents/guardians prior to including the patients in the study. The study was reviewed and approved by the board of the "Giovan Battista Mattei" Research Institute.

\section{Availability of data and material}

The access to datasets generated and/or analyzed during the current study is not publicly available due to the Center's research policy to guarantee the privacy of the participants, whose research data are confidential. Aggregate analyses are however available on reasonable request to the corresponding author.

\section{Authors' contributions}

MG and DG analyzed the data, drafted the initial manuscript and reviewed the manuscript. GB conceptualized, designed the work and collected the data. RP analyzed the data and reviewed the manuscript. MC and EB conceptualized, designed the work and reviewed the manuscript. FM, EN and CF reviewed the manuscript. All authors approved the final manuscript as submitted and agreed to be accountable for all aspects of the work.

\section{Funding}

This research did not receive any specific grant from funding agencies in the public, commercial, or not-for-profit sectors. Professional English language proofreading was financed by the "Giovan Battista Mattei" Research Institute as well as the publication fee. However, no significant funding source could have influenced the outcomes of this work.

\section{Consent for publication}

Not applicable.

\section{Competing interests}

The authors declare that they have the following competing interests to disclose in relation to this paper. MG worked as a consultant doctor at Azienda Consorziale Terme di Comano from April to October 2015. DG worked as a consultant doctor at Azienda Consorziale Terme di Comano from May to September 2016. GB worked as a consultant doctor at Azienda Consorziale Terme di Comano from April to October 2014. RP, FM, EN and CF have no competing interests to disclose in relation to this paper. $\mathrm{MC}$ is the president of the "Giovan Battista Mattei" Research Institute. EB is member of the scientific committee of the "Giovan Battista Mattei" Research Institute. However, no significant competing interest could have influenced the outcomes of this work.

\section{Author details}

'Allergy Unit, Department of Pediatrics, Anna Meyer Children's University Hospital, Florence, Italy. ${ }^{2}$ Post-Graduate School of Dermatology, Section of Dermatology and Venerology, Department of Medicine, University of Verona, Verona, Italy. "Giovan Battista Mattei" Research Institute, Stenico, Italy. ${ }^{4}$ Department of Clinical and Evaluative Epidemiology, Trento Health Service, Trento, Italy. ${ }^{5}$ Dermatology Unit, Department of Pediatrics, Anna Meyer Children's University Hospital, Florence, Italy.

Received: 8 August 2019 Accepted: 19 March 2020

Published online: 23 April 2020

\section{References}

1. Odhiambo JA, Williams HC, Clayton TO, Robertson CF, Asher MI. Global variations in prevalence of eczema symptoms in children from ISAAC phase three. J Allergy Clin Immunol. 2009;124(6):1251-8.

2. Zinelli C, Caffarelli C, Strid J, Jaffe A, Atherton DJ. Measurement of nitric oxide and 8-isoprostane in exhaled breath of children with atopic eczema. Clin Exp Dermatol. 2009;34(5):607-12.

3. Schmitt J, Langan S, Deckert S, Svensson A, von Kobyletzki L, et al. Assessment of clinical signs of atopic dermatitis: a systematic review and recommendation. J Allergy Clin Immunol. 2013;132(6):1337-47.

4. Leshem YA, Hajar T, Hanifin JM, Simpson EL. What the eczema area and severity index score tells us about the severity of atopic dermatitis: an interpretability study. Br J Dermatol. 2015;172(5):1353-7.

5. Kunz B, Oranje AP, Labrèze L Stalder JF, Ring J, et al. Clinical validation and guidelines for the SCORAD index: consensus report of the European task force on atopic dermatitis. Dermatology. 1997;195(1):10-9.

6. Silverberg Jl, Margolis DJ, Boguniewicz M, Fonacier L, Grayson MH, et al. Validation of five patient-reported outcomes for atopic dermatitis severity in adults. Br J Dermatol. 2019. https://doi.org/10.1111/bjd.18002.

7. Stalder JF, Barbarot S, Wollenberg A, Holm EA, De Raeve L, et al. Patient-oriented SCORAD (PO-SCORAD): a new self-assessment scale in atopic dermatitis validated in Europe. Allergy. 2011;66(8):1114-21.

8. Charman CR, Venn AJ, Ravenscroft JC, Williams HC. Translating patient-oriented eczema measure (POEM) scores into clinical practice by suggesting severity strata derived using anchor-based methods. Br J Dermatol. 2013;169(6): 1326-32. 
9. Vakharia PP, Chopra R, Sacotte R, Patel N, Immaneni S, et al. Validation of patient-reported global severity of atopic dermatitis in adults. Allergy. 2018; 73(2):451-8.

10. Lee JY, Kim M, Yang HK, Kim HM, Cho J, et al. Reliability and validity of the atopic dermatitis symptom score (ADSS). Pediatr Allergy Immunol. 2018;29(3):290-5.

11. Koh MJ, Giam YC, Liew HM, Foong AY, Chong JH, et al. Comparison of the simple patient-centric atopic dermatitis scoring system PEST with SCORAD in young children using a Ceramide dominant therapeutic moisturizer. Dermatol Ther (Heidelb). 2017;7(3):383-93.

\section{Publisher's Note}

Springer Nature remains neutral with regard to jurisdictional claims in published maps and institutional affiliations.

Ready to submit your research? Choose BMC and benefit from:

- fast, convenient online submission

- thorough peer review by experienced researchers in your field

- rapid publication on acceptance

- support for research data, including large and complex data types

- gold Open Access which fosters wider collaboration and increased citations

- maximum visibility for your research: over $100 \mathrm{M}$ website views per year

At $\mathrm{BMC}$, research is always in progress.

Learn more biomedcentral.com/submissions 